\title{
Retraction Note to: Composite use of numerical groundwater flow modeling and geoinformatics techniques for monitoring Indus Basin aquifer, Pakistan
}

\author{
Zulfiqar Ahmad • Arshad Ashraf • Alan Fryar • \\ Gulraiz Akhter
}

Published online: 30 April 2015

(C) Springer International Publishing Switzerland 2015

\section{Retraction Note to: Environ Monit Assess (February 2011) 173, Issue 1-4:447-457 DOI 10.1007/s10661-010-1398-3}

This article has been retracted by the Editor-in-Chief following an investigation of a complaint received against it. A careful analysis of the co-authored article titled "Composite use of numerical groundwater flow modeling and geoinformatics techniques for monitoring Indus Basin aquifer, Pakistan"by Zulfiqar Ahmad, Arshad Ashraf, Alan Fryar and Gulraiz Akhter published

The online version of the original article can be found at $\mathrm{http}: / / \mathrm{dx}$.doi. org/10.1007/s10661-010-1398-3.

Z. Ahmad $(\bowtie) \cdot$ G. Akhter

Department of Earth Sciences, Quaid-i-Azam

University, Islamabad, Pakistan

e-mail: fz97@hotmail.com

G. Akhter

e-mail: agulraiz@qau.edu.pk

A. Ashraf

Water Resources Research Institute, National

Agricultural Research Center, Islamabad, Pakistan

e-mail: mashr22@yahoo.com

\section{A. Fryar}

Department of Earth and Environmental Sciences, University of Kentucky, Lexington, KY, USA

e-mail: afryar1@email.uky.edu in Environmental Monitoring and Assessment, February 2011, Volume 173, Issue 1-4, pp 447-457 shows extensive similarities with an article published by Arshad Ashraf and Zulfiqar Ahmad in 2008 titled "Regional groundwater flow modelling of Upper Chaj Doab of Indus Basin, Pakistan using finite element model (Feflow) and geoinformatics" in Geophysical Journal International, Volume 173, pp 17-24.

Given the duplication of content described above, the Environmental Monitoring and Assessment article in question is being retracted. 